Supporting Information for

\title{
Photoluminescent Nanocrystals in a Multicomponent Aluminoborosilicate Glass
}

\author{
Andreia Ruivo ${ }^{1,2}$, Marta Ferro ${ }^{3}$, Suzana M. Andrade ${ }^{4}$, João Rocha ${ }^{5}$, Fernando \\ Pina $^{1}$, César A.T. Laia ${ }^{1^{*}}$
}

${ }^{1}$ LAQV-REQUIMTE, Chemistry Department, Faculty of Science and Technology, Universidade NOVA de Lisboa, 2829-516 Caparica, Portugal. Tel: + 351212948 300;

${ }^{2}$ Research Unit VICARTE, Vidro e Cerâmica para as Artes, Faculty of Science and Technology, Universidade NOVA de Lisboa, 2829-516 Caparica, Portugal. Tel: +351 212947893;

${ }^{3}$ Department of Materials and Ceramic Engineering, CICECO-Aveiro Institute of Materials, University of Aveiro 3810-193 Aveiro, Portugal.

${ }^{4}$ Centro de Química Estrutural, Complexo 1, Instituto Superior Técnico, Universidade Técnica de Lisboa, 1049-001 Lisboa, Portugal;

${ }^{5}$ Department of Chemistry, CICECO-Aveiro Institute of Materials, University of Aveiro $3810-193$ Aveiro, Portugal

*Corresponding author, email: catl@fct.unl.pt and Tel: + 351 212948310;

\section{Fax: + 351212948550}

\section{Supporting Information SI1}

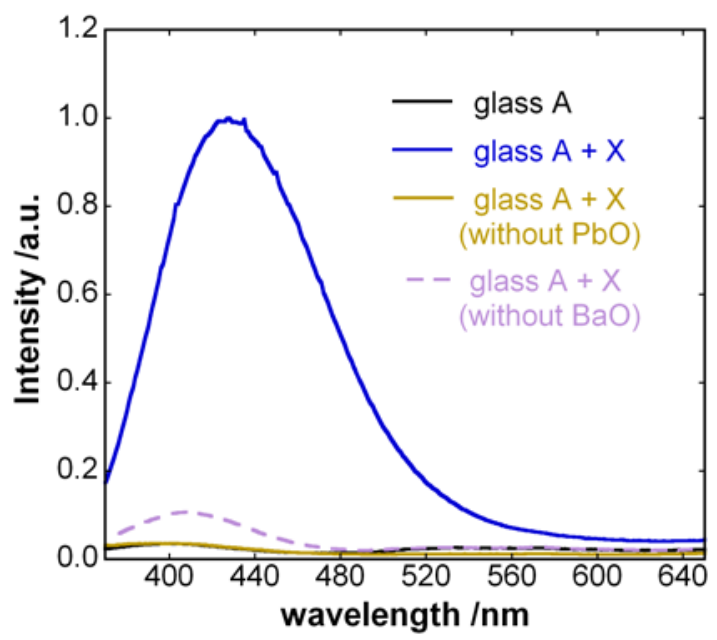

Figure SI 1 - Emission spectra of glass $A$ - base glass, containing $\mathrm{BaO}$ and $\mathrm{PbO}$ (black), $\mathrm{A}+\mathrm{X}$ (strong blue line), $A+X$ - without $\mathrm{PbO}$ (grey line) and $\mathrm{A}+\mathrm{X}$ - without $\mathrm{BaO}$ (light blue line). $\mathrm{X}$ is a mixture of different halogens $-\mathrm{F}, \mathrm{Cl}$ and $\mathrm{Br}$. Glass $\mathrm{A}$ is an aluminoborosilicate base glass. 


\section{Supporting Information SI2}

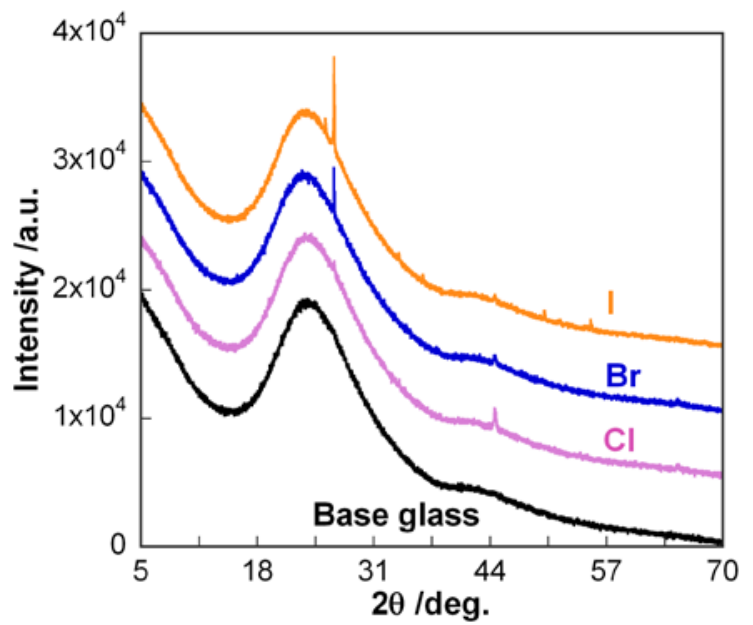

Figure SI2. XRD of the base glass, without halogens (black line) and doped with $\mathrm{NaCl}$ (violet line), $\mathrm{NaBr}$ (blue line) and $\mathrm{Nal}$ (yellow line), from 0 to $70^{\circ}$. 
Supporting Information SI3

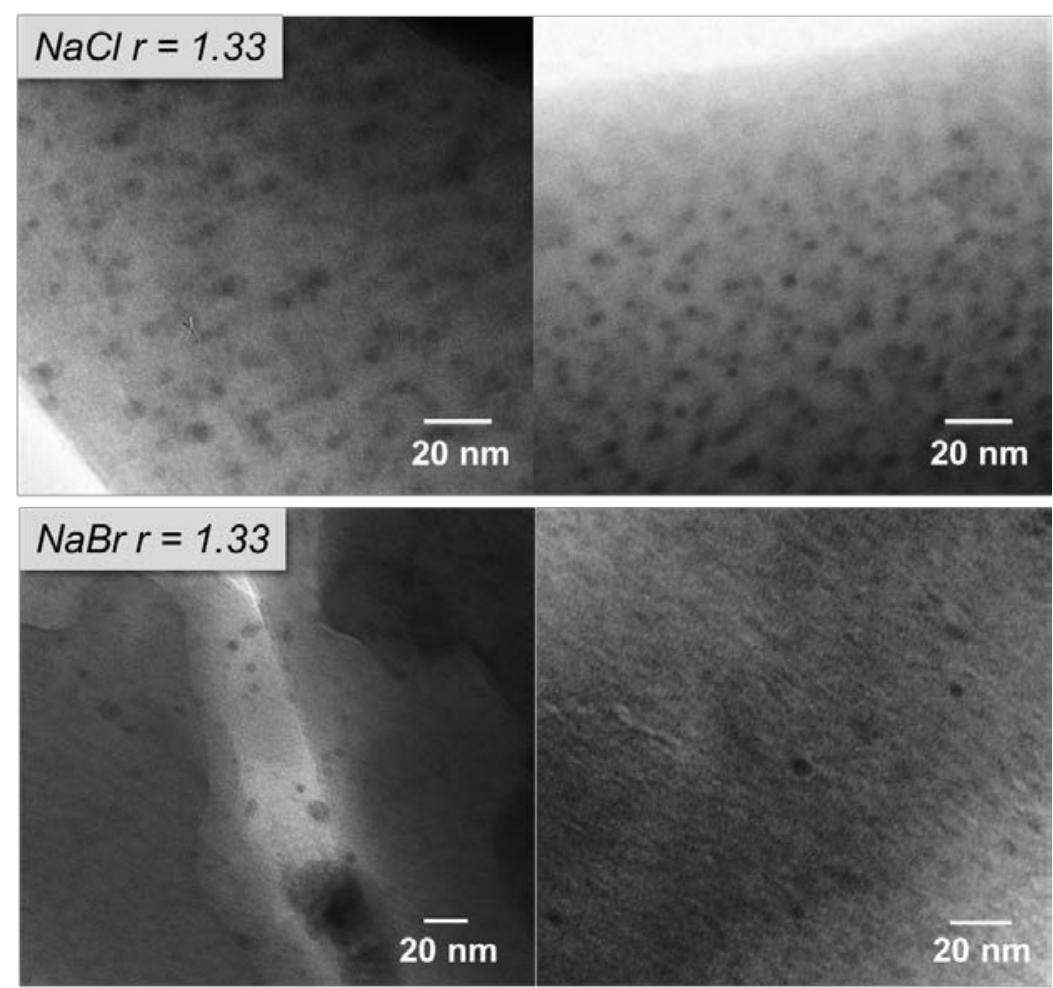




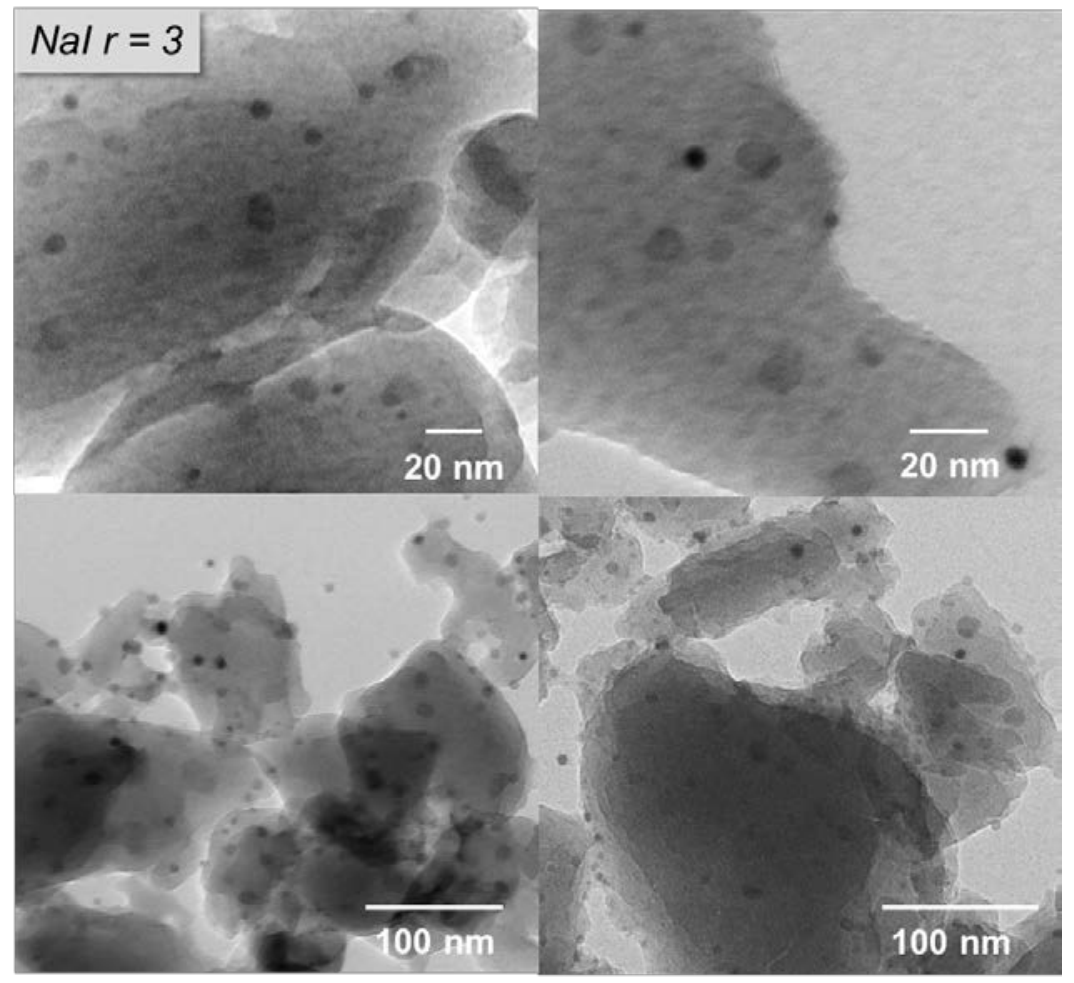

Figure SI 3 - TEM images of halogen ( $\mathrm{Cl}, \mathrm{Br}$ and I) doped glasses; halogen/Pb molar ratio 1.33 for $\mathrm{Cl}$ and $\mathrm{Br}$, and 3 for $\mathrm{I}$. 


\section{Supporting Information SI4}

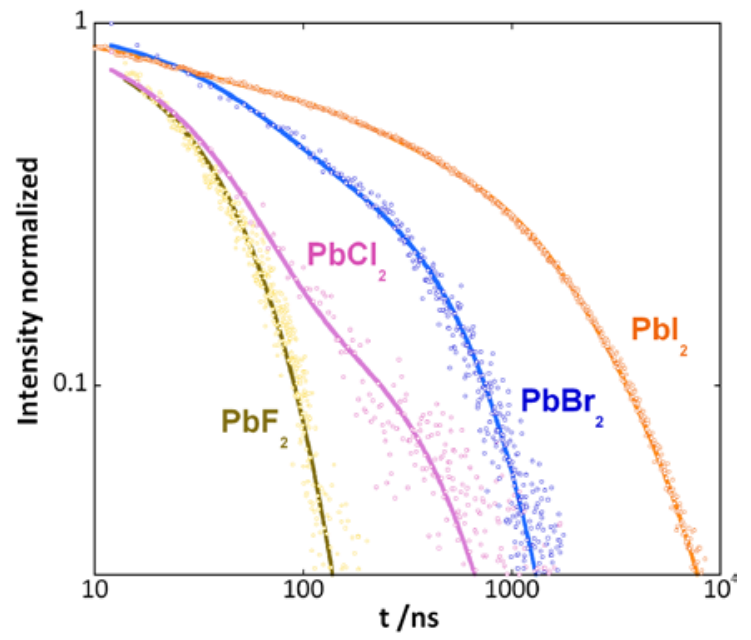

Figure SI 4 - Luminescence decays of aluminoborosilicate glasses doped with different sodium halides synthesized with molar ratio X/Pb=1.33 $\left(\lambda_{\text {exc }}=355 \mathrm{~nm}\right)$. 


\section{Supporting Information SI5}

\section{Glass synthesis}

Several multi-component glasses were synthesized using the following base composition: 63.26 $\mathrm{SiO}_{2}, 16.18 \mathrm{~B}_{2} \mathrm{O}_{3}, 6.29 \mathrm{Al}_{2} \mathrm{O}_{3}, 3.03 \mathrm{BaO}, 3.41 \mathrm{Na}_{2} \mathrm{O}, 1.05 \mathrm{~K}_{2} \mathrm{O}, 5.42 \mathrm{Li}_{2} \mathrm{O}$, and $1.36 \mathrm{PbO}(\%$

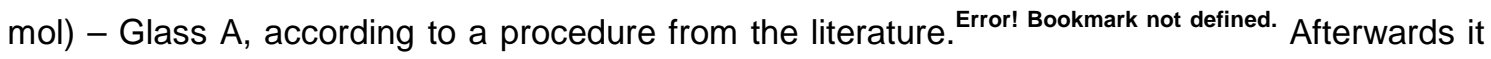
was added to glass $A$ composition different halogens $(X)$, such as $\mathrm{F}^{-}, \mathrm{Cl}^{-}, \mathrm{Br}^{-}$and $\mathrm{I}^{-}$, with a molar ratio $(r)$ of $X / P b=1.33$. In the case of $\mathrm{I}^{-}$, a glass with a different ratio was also produced, $\mathrm{I} / \mathrm{Pb}=3$. Reagent grade $\mathrm{SiO}_{2}$ (p.a., Fluka), $\mathrm{B}_{2} \mathrm{O}_{3}$ (99\%, Acros Organics), $\mathrm{Al}_{2} \mathrm{O}_{3}$ (p.a., Merk), $\mathrm{Pb}_{3} \mathrm{O}_{4}$ (Panreac), $\mathrm{BaO}$ (>98\%, Aldrich), $\mathrm{Li}_{2} \mathrm{CO}_{3}$ (p.a., Fluka), $\mathrm{Na}_{2} \mathrm{CO}_{3}$ (p.a., Riedel de Haen), $\mathrm{K}_{2} \mathrm{CO}_{3}$ (p.a., Panreak), NaF (Merk), NaCl (p.a., Panreak), NaBr (99.5\%, Merck) and Nal (Merk) were used as starting materials. Approximately $30 \mathrm{~g}$ batches were mixed, using a Shaker powder mixer (turbula T2F), and melted inside platinum crucibles in an electric furnace at $1300{ }^{\circ} \mathrm{C}$ for 1.5 hours in air. To be easier to pour the glasses, the temperature was increased to $1400{ }^{\circ} \mathrm{C}$ and then the melted glasses were quenched pouring them into a metal sheet at room temperature, and further annealed at ca. $650{ }^{\circ} \mathrm{C}$ for 15 minutes. The glass samples were cut and polished, for optical measurements, with $0.6 \mathrm{~cm}$ thickness and $0.9 \mathrm{~cm}$ width.

\section{Supporting Information SI6}

Complete reference 21:

Deschler, F.; Price, M.; Pathak, S.; Klintberg, L. E.; Jarausch, D. D.; Higler, R.; Hüttner, S.; Leijtens, T.; Stranks, S. D.; Snaith, H. J.; Atatüre, M.; Phillips, R. T.; Friend, R. H. High Photoluminescence Efficiency and Optically Pumped Lasing in Solution-Processed Mixed Halide Perovskite Semiconductors. J. Phys. Chem. Lett. 2014, 5, 1421-1426. 